\title{
Action Research Implementation in Developing an Open Source and Low Cost Robotic Platform for STEM Education
}

\author{
Avraam \\ Chatzopoulos \\ Dept. of Industrial Design \\ and Production \\ Engineering \\ University of West Attica \\ Athens, Greece
}

\author{
Michail Papoutsidakis \\ Dept. of Industrial Design \\ and Production \\ Engineering \\ University of West Attica \\ Athens, Greece
}

\author{
Michail Kalogiannakis \\ Dep. of Preschool \\ Education, \\ Faculty of Education \\ University of Crete \\ Crete, Greece
}

\author{
Sarantos Psycharis \\ School of Pedagogical \\ and Technological \\ Education \\ ASPETE \\ Athens, Greece
}

\begin{abstract}
The aim of this paper is double: (a) to record the latest theoretical considerations (literature review) in the field of STEM (acronym of Science, Technology, Engineering, Mathematics), Educational Robotics and the Educational Robotic Platforms used in their implementation, and (b) to validate the argumentation on the potential contribution of an Action Research implementation on STEM education with the ultimate goal of designing and developing an "open philosophy", low-cost, hardware and software educational platform for the implementation of STEM and Educational Robotics. This paper is divided into 7 sections: Introduction, STEM Education, Educational Robotics, Problem statement, Action Research, Methodology, and Conclusion. The Introduction introduces the concept and necessity of STEM education approach. STEM Education section reviews recently published scientific literature related to STEM education (literature review) and summarize the pros and barriers of its use in education. Educational Robotics introduces the robotics as an educational tool and presents empirical evidence on its effectiveness. Educational Robot Platforms subsection presents the most popular -along with their main specs- educational robots for STEM and Educational Robotics use. Problem statement section identifies the scientific gap and composes the necessity to implement research (specifically an Action Research) on designing and developing an "open philosophy", low-cost, hardware and software academic platform for the implementation of STEM and Educational Robotics. Action research section reviews recently published scientific literature related to action research. Research Methodology section presents research's proposal development phases and finally, Conclusion summarizes paper's findings.
\end{abstract}

\section{Keywords}

Action Research, STEM, Educational Robotics, Literature Review, Educational Robot Platforms, Open Source, Low Cost.

\section{INTRODUCTION}

In January 2016 [1], [2] former US president Barack Obama "shaken" the existing education system with his weekly speech focusing on his ambitious $\$ 1$ billion private investment plan for improving STEM education, as a direct reflection of US surveys that demonstrated low performance of US students in science and mathematics coupled with their lack of interest in pursuing similar studies [3].
His speech was characterized by many as a shift of formal education in STEM education, while another interesting point was the goal of fairness between places, meaning that all students have the chance to study and be inspired by science, technology, engineering, and math, and have the chance to reach their full potential. Besides, his lasting legacy was the "Educate to Innovate" campaign [4], focusing on the integration of girls and minorities in the STEM disciplines and the elimination of gender inequality through STEM [5].

Future challenges will demand creative solutions, innovation needs to be encouraged, and at the same time the old educational system is not related to the work field, so current curriculum needs to be revisited and rearranged [6]. New-age educational context focuses on changes in education policy and school curricula with a view to competitiveness in the field of science and technology development [7] and, evidence suggests that the US nation will need 1 million more STEM professionals in the coming decade [8].

Employment opportunities are different so it is essential to update the current educational system [6]. STEM education is characterized by team interdisciplinary collaboration that capitalizes on diverse perspectives, knowledge, and skills [9][11]. In this context, USA, European Union and other various countries worldwide integrate STEM programs in primary and secondary education to enforce students to be able to meet the demands of a future workplace and in the wider society [12].

\section{STEM EDUCATION - A LITERATURE REVIEW}

\subsection{Definition}

The term STEM was firstly introduced in the 1990's by the National Science Foundation -previously mentioned as SMET: Science, Math, Engineering, and Technology [13], refers to teaching and learning in the fields of science, technology, engineering, and mathematics, or it is used as a generic label for any action, policy, program or practice that involves one or more of the its disciplines [7].

Other STEM definitions include, Ioannou M \& Bratitsis T [14] whom define STEM education as an integrative approach to curriculum and instruction, content and skills, approaching all its areas as one, without any boundaries between them, while Vasquez, Sneider and Comer [15] mention that STEM education in itself is not a curriculum, but a way of organizing and delivering instruction, and by integrating STEM derivatives there are many benefits that could improve the 
science and mathematics education [10], [16]. More researchers agree that STEM is a learning collaborative environment where students broaden their knowledge and learn through the processes of exploration, invention and discovery using real problems and situations.

According to Ejiwale [17] STEM education is a "metadiscipline" that means the creation of discipline is based on the integration of other disciplinary knowledge into a new 'whole' rather than in bits and pieces. Tsupros, Kohler, \& Hallinen [18] agree that STEM is an interdisciplinary approach where learning happens by integrating the four disciplines into one cohesive teaching and learning paradigm.

At the other hand, Saito, Anwari, Mutakinati, \& Kumano [19] point out that STEM definition is ambiguous and many times although teachers refer to STEM, actually their classes structure and implementation did not reflect the natural interconnectedness of the four STEM areas. For this reason, they don't even try to define STEM, but rather identify several directions of STEM efforts. As well, Yager [20] suggest that the definition of STEM remains unclear and cannot be a scientific term where scientists choose to replace a series of complex observations with a new word.

\subsection{STEM Terms Variations}

Recently, new terms in the STEM acronym are entered for fostering students' innovation and creativity in order to offer a more attractive STEM Education [21].

Table 1. STEM Terms Variations

\begin{tabular}{|c|c|c|}
\hline $\begin{array}{c}\text { Term } \\
\text { (Acronym) }\end{array}$ & Explanation & Source \\
\hline STEAM & STEM and Art & $\begin{array}{l}{[14],} \\
{[22],} \\
{[23]}\end{array}$ \\
\hline STREAM & $\begin{array}{l}\text { STEM and Art, Reading, } \\
\text { Writing }\end{array}$ & $\begin{array}{l}{[14],} \\
{[22],} \\
{[23]}\end{array}$ \\
\hline STEMi & STEM and Innovation & {$[24]$} \\
\hline STEAMi & STEM and Art, Innovation & {$[24]$} \\
\hline $\begin{array}{l}\text { i-STREAM- } \\
\text { e }\end{array}$ & $\begin{array}{l}\text { STEM and Innovation Reading, } \\
\text { Art, Entrepreneurship }\end{array}$ & {$[24]$} \\
\hline STREM & $\begin{array}{c}\text { Science, Technologies, } \\
\text { Robotics, Engineering, } \\
\text { Mathematics }\end{array}$ & {$[25]$} \\
\hline STM & $\begin{array}{c}\text { Scientific, Technical, } \\
\text { Mathematics or Science, } \\
\text { Technology, Medicine or } \\
\text { Scientific, Technical, Medical }\end{array}$ & {$[26]$} \\
\hline eSTEM & Environmental STEM & {$[26]$} \\
\hline STEMIE & $\begin{array}{c}\text { Science, Technology, } \\
\text { Engineering, Mathematics, } \\
\text { Invention, Entrepreneurship }\end{array}$ & {$[26]$} \\
\hline iSTEM & $\begin{array}{c}\text { Invigorating, Science, } \\
\text { Technology, Engineering, } \\
\text { Mathematics }\end{array}$ & {$[26]$} \\
\hline STEMLE & $\begin{array}{c}\text { Science, Technology, } \\
\text { Engineering, Mathematics, } \\
\text { Law, Economics }\end{array}$ & {$[26]$} \\
\hline
\end{tabular}

\begin{tabular}{|c|c|c|}
\hline STEMS^2 & $\begin{array}{c}\text { Science, Technology, } \\
\text { Engineering, Mathematics, } \\
\text { Social Sciences and Sense of } \\
\text { Place }\end{array}$ & [26] \\
\hline METALS & STEAM and Logic & [26] \\
\hline STREM & $\begin{array}{l}\text { Science, Technology, Robotics, } \\
\text { Engineering, and Multimedia }\end{array}$ & [26] \\
\hline STREAM & $\begin{array}{c}\text { Science, Technology, Robotics, } \\
\text { Engineering, Arts, and } \\
\text { Mathematics }\end{array}$ & [26] \\
\hline STEMM & $\begin{array}{c}\text { Science, Technology, } \\
\text { Engineering, Mathematics, and } \\
\text { Medicine }\end{array}$ & [26] \\
\hline AMSEE & $\begin{array}{l}\text { Applied Math, Science, } \\
\text { Engineering, and } \\
\text { Entrepreneurship }\end{array}$ & [26] \\
\hline THAMES & $\begin{array}{l}\text { Technology, Hands-On, Art, } \\
\text { Mathematics, Engineering, } \\
\text { Science }\end{array}$ & [26] \\
\hline MINT & $\begin{array}{l}\text { Mathematics, Informatics, } \\
\text { Natural sciences and } \\
\text { Technology }\end{array}$ & [26] \\
\hline GEMS & $\begin{array}{l}\text { Girls in Engineering, Math, and } \\
\text { Science }\end{array}$ & [26] \\
\hline
\end{tabular}

Therefore, considering all this variety of STEM terms and/or its others permutations becomes clear that STEM is here to stay.

\subsection{STEM Education Integration Approaches}

According to Vasquez, Comer, \& Sneider [15], there are four levels of STEM integration: disciplinary, multidisciplinary, interdisciplinary and transdisciplinary. The descriptions of each level are shown in Fig. 1.

A different -but quite similar- opinion comes from The STEM Education Act of 2015 [19], who defines three classifications of STEM Education: Single STEM Discipline, Multi Disciplines, and Integrative STEM Initiatives, while other researchers [10], [27], [28], suggest that there are only two different approaches to integrate STEM into education:

i. The content integration that focuses on merging content fields into a single teaching activity to highlight "big ideas" from multiple content areas.

ii. The contextual integration that focuses on the content of a single scientific field, while frameworks from other disciplines are used to make the subject more relevant. 


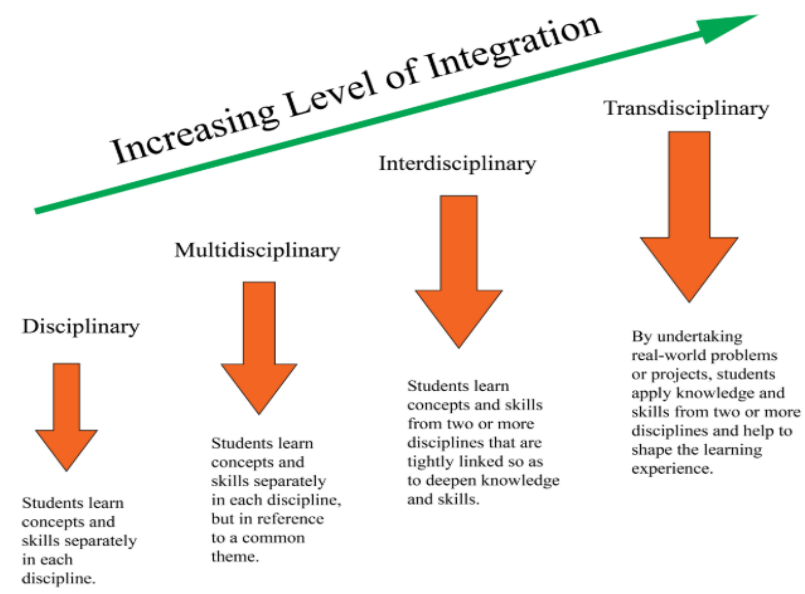

Fig. 1: A continuum of STEM approaches to curriculum integration (Thananuwong, 2015; Vasquez et al., 2013)

As many researchers [19], [25] agree, it is safe to assume that STEM represents an integrated approach of training within which the academic scientific and technical concepts are studied in the context of real-life aiming to the creation of stable relations between school, society, work and the whole world contributing to the competitiveness in world economy [18]. In the same vein, Keefe \& Laidlaw [29] claim that toward the future of education the importance of a strong STEM curriculum is unquestioned, older and new research reinforces this position and reports a vast number of benefits according to STEM education [30], [31].

\subsection{STEM Benefits}

STEM is a collaborative environment that engages students in tackling grand challenges and learning through the process of exploration, discovery, and invention using real problems and situations. Through STEM, students [14], [32]:

i. are encouraged in creatively ideas expression,

ii. motivated in curiosity,

iii. encouraged in thinking in different ways,

iv. fostered teamwork and the sense of belonging,

v. learn to learn from and with others,

vi. develop new skills, technologically literate, and

vii. become competent problem solver, innovative, selfconscious and reasonable thinkers [33].

STEM Education contributes to the bridging of ethnic and gender differences, sometimes encountered in the fields of mathematics and science while at the same time students can develop 21st Century skills like adaptability, problem-solving, complex communication and system thinking [34] to facilitate solving of grand challenges that are not yet solved at the local, national, or global community [4]. In addition to the overall STEM benefits, students that accomplish a STEM program enjoy [35]:

$$
\begin{aligned}
& \text { i. equality in education, } \\
& \text { ii. explore subjects at greater depth, } \\
& \text { iii. develop critical thinking skills, } \\
& \text { iv. are better prepared for the rigors of a } \\
& \text { college/university curriculum. }
\end{aligned}
$$

It is also worth mentioning, that students choose STEM over other fields of study because [35], [36]:

i. They are challenged Intellectually, passionate about field of study and performed well in these subjects.

ii. They are offered a good job potential and enjoy a good salary. STEM occupations generally offer higher wages and additional opportunities for advancement, as compared to non-STEM occupations [8].

iii. There is a need of qualified workers in these fields and STEM concept has received support from government, educators, business and community alike.

iv. They like to make a difference.

\subsection{STEM Barriers and Criticism}

Tucker [37] considers that the whole educational system is the problem, and therefore new educational programs such as STEM education won't have the desired results. For example, it is inconceivable to build a strong STEM secondary curriculum on a weak primary one, especially in the US (and other countries) where elementary school teachers can teach mathematics without ever having taken a college-level math course [35], [38]. To be better prepared, teachers have to invest in their professional development by increasing their confidence and efficacy for teaching STEM [17], [38], [39]. Another drawback of the STEM model is, that educators must develop their own STEM educational model since it does not provide clear guidelines for them to follow [35]. Chen [35] also notes that currently, there are no national standards for STEM education, neither for educators' certification in these programs

In 2008, the Institution of Engineering and Technology [40] provided a report concluding all the major barriers to the uptake of STEM subjects based on evidence from a wide literature review (almost 300 papers). In its summary identifies the following barriers:

i. The need for quality teaching for students to become, and remain, engaged in STEM.

ii. The difficulty of STEM subjects.

iii. The transition from primary to secondary school.

iv. Students gender. It is obvious that males and females have different interests and focus on different things.

v. Perceptions about careers and future opportunities.

vi. The negative views about success and negative stereotypes about STEM.

vii. The role of the influencers (teachers, media and parental influence).

Adding to the above list, [17] addresses the following additional barriers to successful implementation of STEM education:

i. Poor preparation and inspiration of students.

ii. Lack of connection with individual learners. Some connection approaches could be: STEM contests, summer programs and camps, Fablabs, etc.

iii. Limited teachers' research collaboration across STEM fields. 
iv. Poor content preparation, delivery and assessment method.

v. Students limited experience in hands-on training.

vi. Limited funds lead to absent support from the school system.

vii. Poor Condition of laboratory facilities and instructional media.

In the same vein, Chiu et al. [39] distinguish eight different categories of STEM hypothetical barriers of supporting STEM education: values, collaboration and planning, curriculum and instruction, professional learning, communication, partners, technology, and money. The research literature about how to support STEM monetarily is limited and the educational system may not have the resources to provide STEM education for all [41]. Education is an expensive endeavor [39] and Ejiwale [17] admits that many schools are not equipped with the needed facility structure, tools, and equipment to adequately support STEM. A full STEM program needs textbooks, lab spaces, equipment, materials, and curricula which are costly, so it is a top priority to find a way to minimize the above costs when there are no adequate levels of funding for STEM education. Another aspect of the limited money resources for STEM education is the limited and obsolete technology provided by schools. Technology is a tool, should be part of a school and it must not be limited to computer and internet use. Teachers may need to be taught how to use technology in their classrooms as a means to integrate STEM and along with their students should have hands-on experiences with lab spaces and equipment. Technology has the ability to support and enhance science education and while, is not sufficient for effective learning to occur; but, coupled with appropriate scaffolding from teachers and other experts, supports inquiry-based learning [39].

\section{EDUCATIONAL ROBOTICS (ER)}

Educational Robotics (ER) is a broad term referring to a collection of activities, educational programs, technology platforms, educational resources, and pedagogical learning theories, and it is one of the most complete approaches to STEM education model within and outside the school environment [42].

ER is an innovative activity that actively involves students in the learning process. It first appeared in the 1960s when Seymour Papert began to develop new technologies for children and was continued by Mitchel Resnick who since 1980 has been involved in the connection between games, computer and learning. Through its multidisciplinarity, ER can be a powerful tool for designing STEM activities by motivating students to engage with STEM sciences, particularly in Greece where there the only activity presents in STEM approaches in schools, relates to educational robotics applications.

Robotics is an interdisciplinary topic involving components from computer engineering, electrical, electronic, mechanical, and control theory, offering students hands-on exposure to these scientific fields, and it is a useful aid for learning mathematics, technology, science and, computer programming [43], [44]. Robotics might be used as a learning object or as a learning tool. As a learning object robotics on its own can be studied as a subject, while as a learning tool robotics can be used for teaching and learning other subjects such as mathematics and science [43], [45].
Robots -the physical studying objects of the robotics scienceare an excellent vehicle for students to demonstrate basic engineering problems as they help them to develop skills such as problem-solving, designing, teamwork and creativity [44]. Furthermore, Plaza et al. [46] point out that through the use of robotics, it is possible to draw students' attention to educational content that did not motivate them.

According to Alimisis \& Bailakhs [47], [48] there are three different approaches to ER:

i. The Theme-Based Curriculum Approach where curriculum areas are integrated around a special topic for learning.

ii. The Project-Based Approach where students work in groups to explore real-world problems.

iii. The Goal-Oriented Approach where student teams compete in challenges in Robotics Contests, such as the World Robot Olympiad (www.wroassociation.org).

In the same vein, Miller \& Nourbakhsh [49] note three different roles for educational robots:

i. Robot as a programming project, where students have to implement a physical robot programming project.

ii. Robot as a learning focus, when other science courses (e.g. Mechatronics) focus on the creation and use of a physical robot as a goal in and of itself.

iii. Robot as a learning collaborator, where robots serve as a companion, aide to students.

\subsection{Educational Robotics Benefits}

According to Papert, researchers, and educators, ER has numerous advantages and benefits for students [42], [47], [49]-[52]:

i. Improves concentration [51], and the overall learning process at all levels of education, even with students with specific difficulties [42], [50].

ii. Increases motivation to learn [50], [53], promotes socialization and the building of a cooperative environment [54].

iii. Offers hands-on exposure to a wide range of subjects such as mechanical, electrical, and computer engineering and is a useful aid for learning mathematics, technology, science, and computer programming [44], [55].

iv. Remains students' high levels of attention and curiosity [54], while hands-on robotic activities and tasks are fun and attractive for them. Furthermore, can help capture their interest, and build aspirations for future STEM studies [51], [56].

v. Develops cognitive and social skills including teamwork, problem-solving, creativity, and robot design [51].

vi. Attracts students to technological and scientific studies, and increase their academic performance in several courses [57], since engaging in robots enables them to apply and learn knowledge from several technical fields [55].

vii. Man - robot interaction can promote the 
establishment of links between science-technology, education and the humanities [58].

viii. Encouraged students to promote their interest and improve their English ability [50].

\subsection{Educational Robot Platforms}

The first step towards ER and STEM is to choose and use a robotic platform. According to Arvin et al. [59], educational robotic platforms can be split into three categories:

i. manipulators (used for industrial robotics),

ii. legged mobile robots and,

iii. wheeled mobile robots.

Karim, Lemaignan, \& Mondada [60] classify them based on their design and construction complexity to:

i. complex LEGO-like brick-based robot assembly kit,

ii. minimal mobile robot design kit,

iii. robot manipulator design kit,

iv. open-source robot design,

v. pre-assembled desktop robots and,

vi. miniaturized swarm robots.

Another classification from García-Saura \& González-Gómez [61], categories them to commercial and custom, where commercial educational robots (e.g. Lego Mindstorms EV3, VEX IQ, Robotix, Parallex BoeBots, etc.) are available on the market and usually is the easiest option for educators, and custom robots (e.g. Arduino or Raspberry Pi based custom robots) are designed and developed by Universities or the educators themselves providing fully customization, and adaptation for use in different subjects. However, some educators prefer a mixed approach where commercial educational robots are used as the main robotic platform, and custom electronics and/or software are later added e.g. Parallax Boe-Bot3 robot [61].

Furthermore, other considerations such as software hardware specifications, cost, user interface, size, functionality, openness, target group, supported educational material, etc. should be taken into account when selecting the most appropriate robotic platform.

Right now in the market, there is a big variety of robotic platforms (commercial or custom) for STEM and ER usually offered as "ready to use" kits [62], [63]. They both usually contain [51], [64]:

i. a micro-controller which is the control unit; the brain of the robot system,

ii. various sensors to "sense" (detect or measure) environment's physical properties such as temperature, light, touch, sound, humidity, etc.,

iii. various actuators to convert energy into motion, sound, light, heat, etc.,

iv. electronic and hardware stuff: cables, batteries, battery holders, gears, cogs, wheels, trolleys, plastic bricks, plastic or metallic parts and some other components to assembly interesting mechanical constructions e.g. robot cars, robot arms, cranes, drones, watermills, etc.,

v. software to program the micro-controller and, vi. accompanying educational material to support educators and students.

The supporting software and micro controller's programming ability in alternative ways like high-level languages $(\mathrm{C}, \mathrm{C}++$, Visual Basic, Python), web-based applications (e.g. Scratch, Tinkercad, Netsblox), mobile or tablet apps (e.g. Lego WeDo2.0, Bluino, RemoteXY) or ever specialized programs (e.g. Matlab, LabView, ROS), is usually the most basic criterion for choosing an educational robotic kit because it offers or not, users freedom of choice and programming.

When educators are faced with the robotic platform selection dilemma they must take into account that a robotic platform [65], [66]:

1. Should be cheap, to allow one robot per student or working in small groups.

2. Should be robustly built and easy to repair.

3. Robot hardware should be flexible and should be adapted to different circumstances and tasks e.g. easily add or remove different types of sensors and actuators.

4. Easy integration with high-level programming languages by using the same language in programming robots' controller and easily controlling robot from computer.

5. Robot's hardware e.g. microcontroller, sensors, actuators, should be detachable and reusable in future projects. Microcontroller dimension should be small enough to be fit into prototypes of a variety of sizes, and should be versatile in connecting to and interfacing with different types of sensors and actuators, providing -at the same time- more open ports for connections.

6. Robot platform should have a large community behind it, to support students learning from others and sharing with the community of their own.

7. Robots hardware technology should have the ability to be transparent, providing students the intuitive view of the hardware components, while on the other hand giving them a simplified or not too much complicated abstraction of the technology.

8. Wireless communication between the robotic platform and computer is preferred, since in many cases students will need to prototype mobile applications that interact among other systems.

Despite their increased price, the main disadvantage of commercial platforms (e.g. Lego EV3, WeDo, VEX IQ, Meccano, Fischertechnik, etc.) is that they are closed and proprietary, so they are black boxes and not allowed to be used in a different way than have been designed [61]. An additional disadvantage is the possibility of their manufacturing discontinued, meaning that the school's initial investment would be lost and teachers educational material should be re-written. On the other hand, custom educational robots are usually open source, sometimes cheaper (or more expensive, depending on their construction) and the teacher need more time to write educational material since they are unique.

In this point, a new question arises: Is there a way to combine the advantages of both commercial and custom platforms, so to provide a cheap, open source, native language user 
interface, widely accepted educational platform for STEM and ER? And if so, what should be their primary specifications?

\section{PROBLEM STATEMENT}

From the above literature review, it makes sense to conclude that both STEM education and ER are heavily dependent on the appropriate supportive educational environment in respect to human resources and educational tools. Teachers need the right educational robot platforms, specialized hardware, software tools, and educational material to implement STEM and ER, and school need a respectable budget too, so to contributes to the bridging of differences and provide equality in education.

According to Trigo, Standen, \& Cobb [67], educational platforms cost (price) is considered as the major concern and barrier for which a school would not acquire the technology. Other barriers highlighted by teachers as the main reasons why they would not use a robot platform including:

i. lack of a user-friendly interface,

ii. not appropriate contents for their students, so they would like to be able to create their own activities in an easy way,

iii. not being able to use different robots with the same controlling interface so they have to invest in learning and possibly buying two different software systems.

In my personal point of view, there is a need for a new educational tool (platform) suitable and approved from educators and students, specially designed for STEM and ER purposes. A tool designed from / and for the educational community. A native-language tool that could be used on a large scale to support national educational policy for STEM education. The desired specs should be:

1. Very cheap to support a low budget in big quantities, so to may support national policy for STEM education penetration, even for the third world countries.

2. Native language-oriented, meaning that both hardware guidelines, software user interface, and educational material should not only be available in English or other popular languages. Furthermore, easy language customization should be an option.

3. Fully open source so to easily be customized, freely available and be supported by community.

4. A fully integrated ecosystem, meaning a unified environment that successfully involves and collaborates hardware, software and educational material. A different approach for students/teachers. Truly attractive to engage educators, students, developers, stakeholders and the whole community to participate.

5. Focus on ease of use, flexible expandable, easy installation and maintenance, ready-made examples, educational material templates, and lesson plans.

6. Certainly, web-based, meaning no need for special hardware (able to operate with smartphones, tablets, PCs) and/or software (e.g. operating systems, highlevel languages). Additionally, support for already software tools used in robotics.

\section{Wireless and/or wired operation.}

8. 3D-printable hardware should be an option, so to be easily be built at school, fab lab, or ever at students' - teachers' homes. Printbots suggested by García-Saura \& González-Gómez [61], could be a starting point for designing custom robots with very little effort.

In this point, a secondary question arises: A new innovative educational platform, designed by whom? By engineers, teachers, students or who else?

\subsection{Scientific objectives and research questions}

The main purpose of this research proposal is to design and develop -through a participatory action research- an open source, multi-language, low cost, hardware and software robotic platform to implement STEM and ER in primary education. The design and development of the platform will focus on both students' views and observations, and educators' needs and teaching requirements. The central axis of the educational platform would be the Internet where users (teachers, students, stakeholders) and devices (educational robots, STEM hardware) would be connected. During the design phase, special attention will be given to the educational platform to:

i. Be compatible with older technology equipment (e.g. PCs) so to limit technological exclusion, economic weaker user groups and new school's investments in hardware.

ii. Be based on open source standards and technologies such as "Arduino" project.

iii. Provides collaborative tools to enhance teamwork.

iv. Offers a contemporary, attractive user interface in accordance with user suggestions.

Research proposal's scientific objectives would be:

i. To enhance collaboration, communication, and teamwork.

ii. Not to exclude vulnerable social groups.

iii. To focus on the development of STEM activities, particularly in ER, focusing on the use of recycling materials as building blocks.

iv. To optimum use of modern learning theories scientific principles.

The research questions to be explored are the following:

1. Can a participatory action research contribute to the design and development of an educational platform for STEM and ER applications?

2. Can students make an effective contribution to the development of educational products that concern them?

3. How effectively can an educational platform for STEM applications be used without teachers' support to students for STEM applications?

4. How can Free and Open-Source Software (FOSS) be used to disseminate new products - services? 


\subsection{Research contribution and originality}

The originality of this research proposal is that the delivered educational product (hardware and software robotic platform), is a derivative of educational participatory action research and equal treatment of students as active members of the educational community, with the ultimate goal of contributing themselves to learning activities.

Students, in collaboration with educators, think, propose, judge, evaluate and give feedback to the researcher with valuable observations that will be used in designing and developing the educational platform, as opposed to the established way of designing the life-cycle of a hardwaresoftware system where the working phases are specified by system engineers and subsequently evaluated by consumers [68].

Research proposal's contribution is summarized as follows:

i. Contribution to equal treatment of teachers students, as the proposed educational platform through action research- will be based on their proposals and remarks.

ii. Contribution to the Greek educational STEM and ER community. Platform's adaptation to the need and peculiarities of the Greek educational community is one of the main research's objectives.

iii. Contribution to the elimination of social inequalities. Low-cost production, open philosophy, and the freedom to choose materials - components contribute to a product accessible and available to everyone.

iv. Contribution to "educational isolation" of underdeveloped countries economies, as the platform's main goal is to keep costs as low as possible, and the additional workplace requirements to a minimum.

v. Contribution to the FOSS concept, since hardware and software will be freely provided to the educational community under Creative Commons licenses.

\subsection{Research's necessity and importance}

STEM education faces several challenges in practice since it requires the existence of an organized environment, the necessary infrastructure (STEM and robot platforms, specialized software, suitably designed spaces, labs, etc.), and of course the appropriated trained educators who will be responsible for coordinating the learning process.

Several publications [17], [40], [69]-[74], have identified potential obstacles, problems, and challenges faced by teachers in the successful STEM education implementation, including:

i. Inability to find authentic problems.

ii. Lack of knowledge and inability of teachers' collaboration.

iii. The probability of failure.

iv. Education system's lack of support.

v. Poor students' preparation.

\section{ACTION RESEARCH}

\subsection{Definition}

According to Kemmis, Nixon, McTaggart, [75], action research's $(A R)$ definition and concept are numerous and different and vary according to space, place, and context. Billett, Harteis, \& Gruber [76], agree with this view and believe that it is not possible to be described as a specific design or in a uniform way.

AR was originally introduced by social psychologist Kurt Lewin and John Collier [77, p. 30] in the 1940s, aiming to involve social groups with researchers in making joint decisions on problems for further social and cultural changes, by codifying the research process into four main stages [78]:

$$
\begin{array}{cl}
\text { i. } & \text { planning, } \\
\text { ii. } & \text { acting, } \\
\text { iii. } & \text { observing, } \\
\text { iv. } & \text { reflecting. }
\end{array}
$$

At least two are the main stages of AR's history: Kurt Lewin's first stage initial practices and early 1970's a renewed interest in educational research [77], with a clear purpose to motivate teachers' professionalization improvement, by giving them a researcher role to allow assessing curricular guidelines in the classroom, and improve teaching practices [79].

AR enables stakeholders and members of a community to participate in the project and to provide valuable input, as well as interventions and actions that promote change. Cohen, Manion, Morrison \&Villanueva, [80], [81], characterize it as research which seeks to exploit data that has been found after deliberate and systematic cooperation to solve practical problems in a particular region with a view to improving it. In the same vein, Calhoun, Carr \& Kemmis, [82], [83] define it as a continual professional development - a direct route to improving teaching and learning, a continual disciplined inquiry conducted to inform and improve educators' practice. And moreover, the research literature has long indicated that $\mathrm{AR}$ allows teachers to derive their own theories from action [84].

AR is a methodology for researchers (often teachers) to understand and generate knowledge about educational practices and their complexity, in order to examine their practice if they are as they would like, and maybe to improve it [85]. It could also help their students from benefitting from an enriched learning experience by being exposed to different ways of learning from which their teachers have tested and tried [81]. As is noted below, educational action research (EAR) specifically, is a term used to describe a family of activities in curriculum development, professional development, school improvement programs, and systems planning and policy development [83]. Nowadays, AR is also used in other scientific areas such as management, nursing, and information systems to support the role of researching in their daily activities [79].

According to the convergence definitions points given by Lewin, McNiff, Elliott, Lomax, Kemmis, AR:

i. is a short-range action,

ii. carried out by the participants themselves,

iii. researcher is also a research subject who improve his professional practice, 
iv. other people in the same community are also involved: they are exploring to understand and intervene to improve,

and it aims at improvements in three areas:

i. practice's improvements [81], [85],

ii. practice's understanding by its practitioners and,

iii. improvement of the situation in which the practice takes place [83].

\subsection{Action Research Approaches and}

\section{Modes}

There are many different approaches to conducting AR, depending of:

i. purposes, epistemologies, theories, research traditions, processes, intended learning outcomes and,

ii. people, organizations, communities, contexts, social problems or issues involved [86].

However, its main kinds and derivatives with regard to their key characteristics are the following [85], [86]:

i. Action learning $(A L)$ means learning from and with one another in 'sets' or support groups.

ii. Lifelong action learning (LAL) integrates the concepts of action learning and lifelong learning.

iii. Traditional or practical action research (AR) involves solving social problems individually or collaboratively, and making the results public.

iv. Action learning action research (ALAR), an integrated concept of inquiry, which uses $\mathrm{AL}$ processes and AR principles, following the same philosophy, paradigm and methods

v. Educational action research (EAR) aims to improve learning, teaching, curriculum and administration at schools in higher education.

vi. Collaborative action learning (CAR) usually includes EAR, and is conducted by a group of people who work with or without a facilitator or educational researcher.

vii. Participatory action learning (PAR) is like CAR, aiming at inclusion, social justice and equality of participants in the research.

viii. Critical participatory action learning (CPAR) aiming at social justice and participants' emancipation from a critical theorist perspective.

ix. Participatory action learning and action research (PALAR) which is an integrated concept of ALAR, PAR and lifelong AL, aiming at positive social change for a just and better world for all human beings.

And many others, -to name some- including critical action research, diagnostic action research, practitioner research, classroom-based action research, empirical action research, action science, appreciative inquiry [85].

Carr \& Kemmis [83], identifie three different AR's kinds -or modes, according to Newton \& Burgess [87]- based on the different role of the researcher can take: i. Technical action research aims to improve the effectiveness of educational practice judged by the educational researcher's standards where the practitioners are co-opted and depend greatly upon him.

ii. Practical action research aims at the practitioners understanding and professional learning, where the researcher's role is to encourage the participants practical deliberation and self-reflection.

iii. Emancipatory action research aims at a critical response to organizational constraints, where educational researcher's role is that of a moderator who ensures that conditions are established and maintained which are necessary for the 'organization of enlightenment' [86].

Similarly, Lune \& Berg [88], suggest these modes of AR based on the goals and purposes of the inquiry:

i. technical / scientific / collaborative

ii. practical / mutual collaborative / deliberative, and

iii. emancipating / enhancing / critical science.

In addition, Newton \& Burgess [87], suggest the following commensurable action research's modes, resonate more in understanding the nature of inquiry in educational institutions:

i. a knowledge-generating mode,

ii. a practical (improvement of practice) mode, and

iii. an emancipatory mode.

Various methods can be used in the context of AR, to collect data for the fullest, most case appropriate, and validity of results findings, such as [75], [77], [89], [90]:

i. Observation (research calendars, checklists, notes, document analysis, tape recordings, photography, video recording, written texts, worksheets).

ii. Interviews.

iii. Questionnaires, rubrics, surveys.

iv. Or other techniques such as knowledge games, roles, case study, biographical method, discussion / focus groups, pre- and port- tests, etc.

The above methods' combination is called "triangulation" gathers data from at least three different perspectives angles and allows the confrontation and comparison of different descriptions of the same situation [77, p. 168].

\subsection{Action Research Methodology}

Although, in the literature [75], [91], several AR models are available [92], almost all of them accept the circular or spiral process (Fig. 2, Fig. 5). 


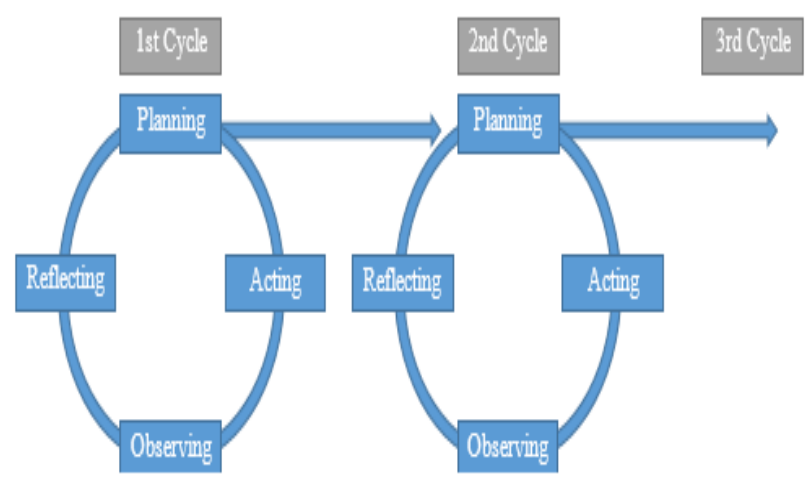

Fig. 2: Action research cycles

The most common one was introduced by Lewin, is a selfreflective spiral of cycles (Fig. 2), where one stage of the research includes phases of (i) planning, (ii) action, (iii) observation and (iv) evaluation or reflection which then lead into further cycles where the stages are repeated [83], [92], [93]. In the same spirit Greeff, Coetzee \& Ortrun ZuberSkerritt [94], [95] suggest the following five steps (Fig. 3) to establish AR:
i. Identify the problem.
ii. Data collection and organization.
iii. Data interpretation and action planning.
iv. Action implementation based on data findings.
v. Evaluation, critical reflection of result.

The knowledge gained from the initial cycle feeds the programming of the second cycle for which AR is modified and the research process repeated [78].

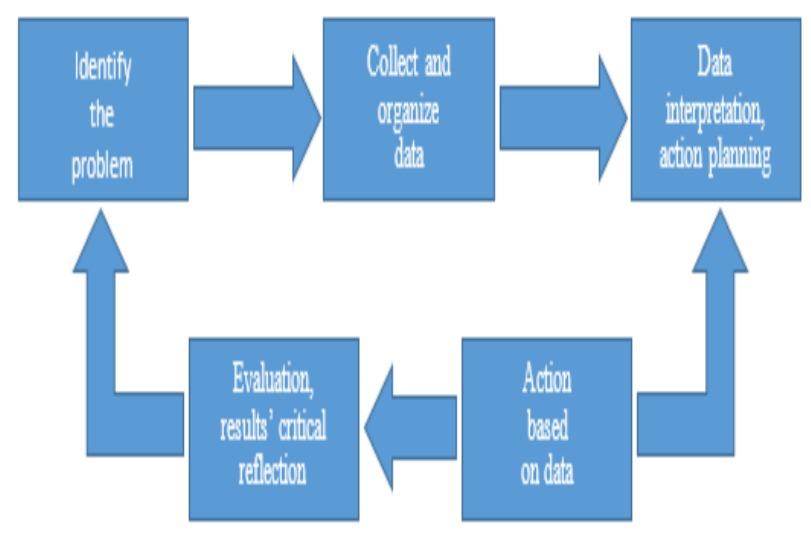

Fig. 3: Action research stages

Bassey [96] suggests an alternative eight-stage AR model [85]:

i. Defining the inquiry.

ii. Describing the educational context and situation.

iii. Collecting evaluative and analyzing data.

iv. Reviewing the data and looking for contradictions.

v. Tackling a contradiction by introducing change.

vi. Monitoring the change.

vii. Analyzing evaluative data about the change. viii. Reviewing the change and deciding what to do next.

Likewise, Cohen, Manion \& Morrison introduce an eightstage model (Fig. 4) that does not necessarily follow a linear sequence, and steps may be recursive and in a different sequence [85].

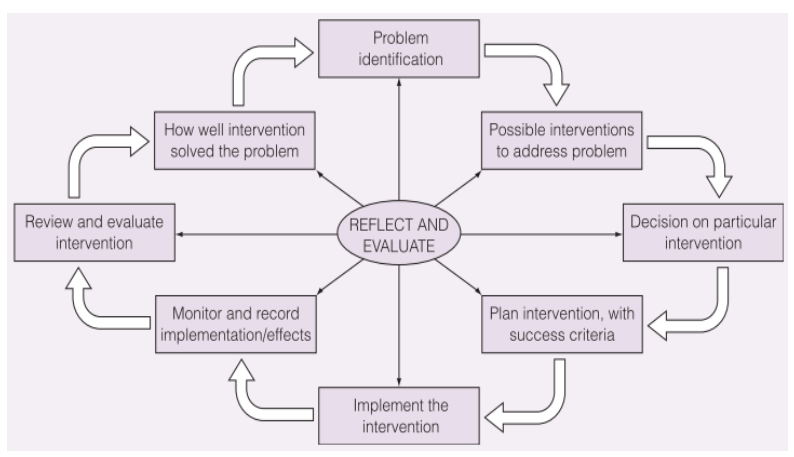

Fig. 4: A framework for action research [91, p. 451]

\subsection{Action Research \& STEM}

A systematic approach was followed in order to research for STEM - ER papers relative to AR. While some of the findings involves these terms e.g. [97]-[105], as far as I have researched, no study has been conducted on an AR implementation in designing and developing a hardware and software robot platform for STEM education and ER. So, it is safe to assume that this research proposal contains originality that may have an interest in exploring.

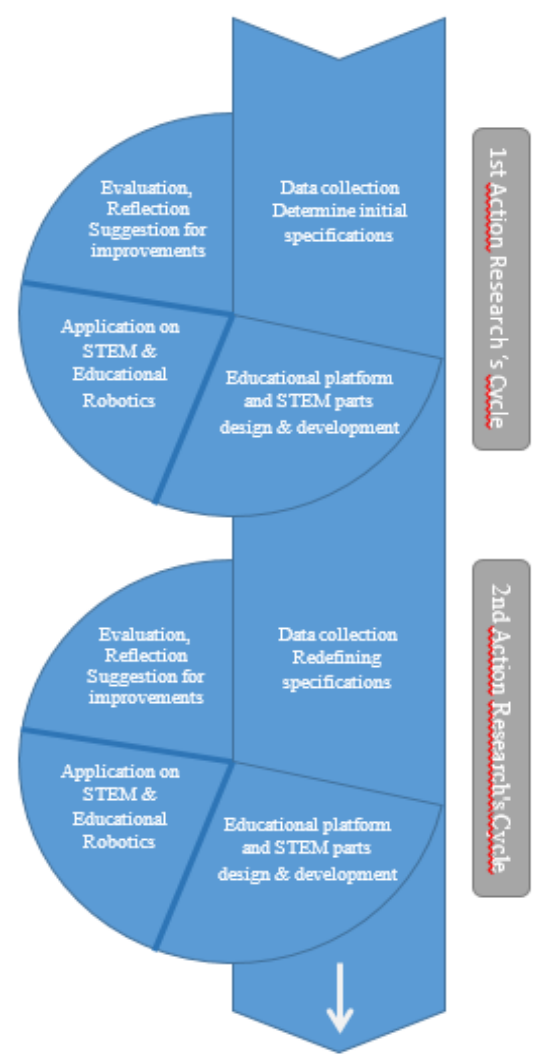

Fig. 5: Action research's cycles 


\section{RESEARCH METHODOLOGY}

The following four phases will be followed by this research proposal:

1st Phase: Literature review.

2nd Phase: 1st cycle of AR. Survey's preparation.

3rd Phase: 2nd cycle of AR. Theory's implementation in practice: educational platform's development.

4th Phase: 3rd cycle of AR. Completion, evaluation, reflection.

There may be additional phases (AR's cycles) as shown in Fig. 5 that repeat the three last -due to the spiral structure of the AR- but that will depend on the 4th phase's results and conclusions evaluation.

\section{ACKNOWLEDGMENTS}

All authors would like to thank the University of West Attica and specifically the Post Graduate Program of Studies (MSc) "New Technologies in Shipping and Transportations", for the financial support provided to them to undertake this research project.

\section{CONCLUSION}

According to Dr. John Moder, "STEM education is a common good. If we don't make the investment, we all suffer. If we don't take advantage of the emerging majority of the country-[the nation] is going to be in bad shape." [8]. In the literature, there is strong evidence that shows Moder's view is shared by many other researchers [19], [43], [106]-[113]. STEM's implementation focuses on the non-exclusion of vulnerable social groups such as girls, minorities and economically weak students and while, there is a literature wealth focusing on educational activities and ways of integrating STEM into educational activities, few - if not at all - research focuses on educational tools specifically for STEM activities. Many commercial products are on the market, however, their expensive price and their closed architecture are prohibitive to a large-scale national educational STEM integration [114-115]. A need for a tool -suggested by the stakeholders themselves- that supports both teachers and students with open source hardware/software, educational lessons plans and guidelines and, a strong community to interact, is what this paper is all about.

\section{REFERENCES}

[1] Jo Handelsman and M. Smith, "STEM for All," 2016. [Online]. Available: https://obamawhitehouse.archives.gov/blog/2016/02/11/s tem-all. [Accessed: 06-Mar-2018].

[2] B. Obama, "Giving Every Student an Opportunity to Learn Through Computer Science For All," 2016 [Online]. Available: https://obamawhitehouse.archives.gov/the-pressoffice/2016/01/30/weekly-address-giving-every-studentopportunity-learn-through-computer. [Accessed: 06-Mar2018].

[3] J. J. Kuenzi, "Science, Technology, Engineering, and Mathematics ( STEM) Education: Background, Federal Policy, and Legislative Action," Energy, no. RL33434, pp. 1-7, 2008.

[4] Courtney Tanenbaum, "STEM 2026: A Vision for Innovation in STEM Education," 2016.

[5] N. Salim, "S.T.E.M: President Obama's lasting legacy of equality," The Hill, 2016. [Online]. Available: http://thehill.com/blogs/congress-

blog/technology/283482-stem-president-obamas-lastinglegacy-of-equality. [Accessed: 06-Mar-2018].

[6] M. Hausner, P. Karypidou, M. G. Popescu, L. Bozzo, O. Mihova, and P. Mikše, "STEMART = STEM + ART : An Erasmus + STEAM project for K-12 education," in Hellenic Conference on Innovating STEM Education, 2016.

[7] H. B. Gonzalez and J. J.Kuenzi, "Science, technology, engineering, and mathematics (STEM): A Primer," Congr. Res. Serv., no. August, pp. 1-15, 2012.

[8] Lorelle L. Espinosa, K. McGuire, and L. M. Jackson, "Minority Serving Institutions: America's Underutilized Resource for Strengthening the STEM Workforce," The National Academies Press, Washington, DC, 2019.

[9] N. R. Council, Exploring the Intersection of Science Education and 21st Century Skills: A Workshop Summary. Washington, DC: The National Academies Press, 2015

[10] S. Psycharis, "STEAM in educations: A literature review on the role of Computational Thinking, Engineering Epistemology and Computational Science. Computational STEAM Pedagogy ( CSP )," vol. 4, no. 2 pp. 51-72, 2018

[11] S. Psycharis, E. Botsari, P. Mantas, and D. Loukeris, "The impact of the computational inquiry based experiment on metacognitive experiences, modelling indicators and learning performance," Comput. Educ., vol. 72, pp. 90-99, 2014.

[12] S. Doukakis, S. Katsoulis, and I. Pylioti, "Exploring students knowledge and interesting concerning STEM field," in Hellenic Conference on Innovating STEM Education, 2016

[13] F. Wikipedia, "Science, technology, engineering, and mathematics," wikipedia.org, 2018. [Online]. Available: https://en.wikipedia.org/wiki/Science,_technology,_engi neering,_and_mathematics. [Accessed: 06-Mar-2018].

[14] Ioannou M and Bratitsis T, "Utilizing Sphero for a speed related STEM activity in Kindergarten," in Hellenic Conference on Innovating STEM Education, 2016.

[15] J. A. Vasquez, M. Comer, and C. Sneider, STEM Lesson Essentials, Grades 3-8: Integrating Science, Technology, Engineering, and Mathematics, 1st editio. Portsmouth, NH: Heinemann, 2013

[16] S. Heilig, "K-12 STEM Education," The Institute for the promotion of teaching science and technology, vol. 1, no. 2, p. 112, 2015

[17] J. A. Ejiwale, "Barriers to Successful Implementation of STEM Education,” J. Educ. Learn., vol. 7, no. 2, pp. 63 74, 2013.

[18] N. Tsupros, R. Kohler, and J. Hallinen, "STEM Education in Southwestern Pennsylvania the missing components," 2009.

[19] T. Saito, I. Anwari, L. Mutakinati, and Y. Kumano, "A look at relationships (Part I): Supporting theories of STEM integrated learning environment in a classroom A historical approach," K-12 STEM Educ., vol. 2, no. 2, pp. 51-61, 2016. 
[20] R. E. Yager, "STEM: A Focus for Current Science Education Reforms," vol. 1, no. 1, pp. 1-4, 2015.

[21] D. Connolly, "STEM vs STEAM," Make them Mainstream | Female STEM Education, 2018. [Online]. Available: https://makethemmainstream.com/stem-vssteam/. [Accessed: 20-Mar-2019].

[22] A. Pietrowski, "The Differences of STEM vs. STEAM Education (and the Rise of STREAM)," EdTech, 2017. [Online]. Available: https://edtechmagazine.com/k12/article/2017/08/historystem-vs-steam-education-and-rise-stream. [Accessed: 20Mar-2019].

[23] M. Root-Bernstein and R. Root-Bernstein, "From STEM to STEAM to STREAM: wRiting as an Essential Component of Science Education," PsychologyToday, $2011 . \quad$ [Online]. Available: https://www.psychologytoday.com/us/blog/imagine/2011 03/stem-steam-stream-writing-essential-componentscience-education. [Accessed: 21-Mar-2019].

[24] J. Weidemann, "STEM vs STEAM: what about iSTREAM-e?," The STEM Blog South Africa, 2018. [Online]. Available: https://thestemblogsa.co.za/2018/05/stem-vs-steam/. [Accessed: 21-Mar-2019]

[25] Z. E. Tompieva, S. K. Azhigenova, M. A. Mayasarova, and A. S. Zhantuganova, "Development of STEMEducation in the world and Kazakhstan," Білімді ел Образованная страна, vol. 20, no. 57, pp. 2013-2015, 2016.

[26] Wikipedia, "Science, technology, engineering, and mathematics - Wikipedia," wikipedia.org, 2019. [Online]. Available: https://en.wikipedia.org/wiki/Science,_technology,_engi neering,_and_mathematics. [Accessed: 27-Mar-2019].

[27] G. H. Roehrig, T. J. Moore, and H. Wang, "Is Adding the E Enough?: Investigating the Impact of K-12 Engineering Standards on the Implementation of STEM Integration.," Sch. Eng. Educ. Fac. Publ., 2012.

[28] T. Saito, Y. Gunji, and Y. Kumano, "The Problem about Technology in STEM Education: Some Findings from Action Research on the Professional Development \& Integrated STEM Lessons in Informal Fields," K-12 STEM Educ., vol. 1, no. January, pp. 85-100, 2015.

[29] D. F. Keefe and D. H. Laidlaw, "Virtual reality data visualization for team-based STEAM education: Tools, methods, and lessons learned," Lect. Notes Comput. Sci. (including Subser. Lect. Notes Artif. Intell. Lect. Notes Bioinformatics), vol. 8022 LNCS, no. PART 2, pp. 179187, 2013.

[30] Bybee and W. Rodger, "Advancing STEM Education: A 2020 Vision," Technol. Eng. Teach., vol. 70, no. 1, pp. 30-35, 2010.

[31] J. S. Morrison, "Attributes of STEM education: the students, the academy, the classroom," TIES STEM Educ. Monogr. Ser., 2006.

[32] English Learners in STEM Subjects: Transforming Classrooms, Schools, and Lives (2018). Washington, DC: National Academy of Sciences, 2018.

[33] J. Morrison and R. V Bartlett, "STEM as a Curriculum,"
Education Week, 2009. [Online]. Available: papers3://publication/uuid/48C36DF6-30CA-42ED876D-0D4214A1F890.

[34] N. R. Council, Exploring the Intersection of Science Education and 21st Century Skills: A Workshop Summary. Washington, DC: The National Academies Press, 2010.

[35] G. Chen, "The Rising Popularity of STEM: A Crossroads in Public Education or a Passing Trend?," Public School Review, 2018. [Online]. Available: https://www.publicschoolreview.com/blog/the-risingpopularity-of-stem-a-crossroads-in-public-education-ora-passing-trend. [Accessed: 27-Mar-2019].

[36] D. Long, "STEM Education - STEM Research - STEM Reports," Catapult X, 2018. [Online]. Available: https://www.stemreports.com. [Accessed: 28-Mar-2019].

[37] M. Tucker, "STEM: Why It Makes No Sense," Editorial Projects in Education, 2012. [Online]. Available: http://blogs.edweek.org/edweek/top_performers/2012/06/ stem_why_it_makes_no_sense.html. [Accessed: 27-Mar2019].

[38] S. Portz, "The Challenges of STEM Education Scholarly Commons Citation," 43rd Sp. Congr., vol. 2015, 2015.

[39] A. Chiu, C. A. Price, E. Ovrahim, and M. Ed, "Supporting elementary and middle school STEM education at the whole-school level: A review of the literature," Museum Sci. Ind. Chicago, pp. 1-21, 2015.

[40] Lyn Haynes, "Studying Stem: what are the barriers? The Institution of Engineering and Technology Enquiries to," The Institution of Engineering and Technology (IET). p. $18,2008$.

[41] J. D. Basham, M. Israel, and K. Maynard, "An Ecological Model of STEM Education: Operationalizing STEM for All," J. Spec. Educ. Technol., vol. 25, no. 3 , pp. 9-19, 2015.

[42] L. Daniela and M. D. Lytras, "Educational Robotics for Inclusive Education," Technol. Knowl. Learn., no. 0123456789, 2018

[43] A. Khanlari, "Effects of educational robots on learning STEM and on students' attitude toward STEM," 2013 IEEE 5th Int. Conf. Eng. Educ. Aligning Eng. Educ. with Ind. Needs Nation Dev. ICEED 2013, no. 1, pp. 62-66, 2014.

[44] B. Wagner, P. Hohmann, U. Gerecke, and C. Brenneke, "Technical Framework for Robot Platforms in Education," in International Conference on Engineering Education and Research "Progress Through Partnership," 2004, pp. 699-703.

[45] D. Alimisis, Teacher education on robotics-enhanced constructivist pedagogical methods. 2009.

[46] P. Plaza, E. Sancristobal, G. Carro, M. Castro, M. Blazquez, and A. Peixoto, "Traffic lights through multiple robotic educational tools," IEEE Glob. Eng. Educ. Conf. EDUCON, vol. 2018-April, pp. 2015-2020, 2018.

[47] D. Alimisis, "Educational robotics: Open questions and new challenges," Themes Sci. Technol. Educ., vol. 6, no. 1, pp. 63-71, 2013. 
[48] D. Bailakhs, "Evaluation of Educational Information Systems: The case of MIXATRON in mechatronic education," 2018.

[49] D. P. Miller and I. Nourbakhsh, "Robotics for Education," Springer Handb. Robot., pp. 2115-2134, 2016.

[50] K. Y. Chin, Z. W. Hong, and Y. L. Chen, "Impact of using an educational robot-based learning system on students' motivation in elementary education," IEEE Trans. Learn. Technol., vol. 7, no. 4, pp. 333-345, 2014.

[51] S. Kucuk and B. Sisman, "Behavioral patterns of elementary students and teachers in one-to-one robotics instruction," Comput. Educ., vol. 111, pp. 31-43, 2017.

[52] A. Sullivan and M. U. Bers, "Dancing robots: integrating art, music, and robotics in Singapore's early childhood centers," Int. J. Technol. Des. Educ., vol. 28, no. 2, pp. 325-346, 2018.

[53] F. Mondada et al., "The e-puck , a Robot Designed for Education in Engineering," 9th Conf. Auton. Robot Syst. Compet., vol. 1, no. 1, pp. 59-65, 2006.

[54] G. B. Ronsivalle, A. Boldi, V. Gusella, C. Inama, and S. Carta, "How to Implement Educational Robotics' Programs in Italian Schools: A Brief Guideline According to an Instructional Design Point of View," Technol. Knowl. Learn., no. 0123456789, 2018.

[55] A. Xatzopoulos, M. Papoutsidakis, and G. Chamilothoris, "Mobile Robotic Platforms as Educational Tools in Mechatronics Engineering," in International Scientific Conference eRA - 8, 2013, pp. 41-51.

[56] C. Chalmers, "Robotics and computational thinking in primary school," Int. J. Child-Computer Interact., vol. 17 , pp. 93-100, 2018.

[57] N. C. Zygouris, A. Striftou, A. N. Dadaliaris, G. I. Stamoulis, A. C. Xenakis, and D. Vavougios, "The use of LEGO mindstorms in elementary schools," IEEE Glob. Eng. Educ. Conf. EDUCON, no. April, pp. 514$516,2017$.

[58] L. Armesto, P. Fuentes-Durá, and D. Perry, "Low-cost Printable Robots in Education," J. Intell. Robot. Syst., vol. 81, no. 1, pp. 5-24, 2015

[59] F. Arvin, J. Espinosa, B. Bird, A. West, S. Watson, and B. Lennox, "Mona: an Affordable Open-Source Mobile Robot for Education and Research," J. Intell. Robot. Syst. Theory Appl., pp. 1-15, 2018.

[60] M. E. Karim, S. S. Lemaignan, and F. Mondada, "A review: Can robots reshape K-12 STEM education? 2015_ehsan_CanRobotsReshapeStemEducation.pdf," Adv. Robot. its Soc. Impacts (ARSO), 2015 IEEE Int. Work., vol. 2016-March, p. 8, 2015.

[61] C. García-Saura and J. González-Gómez, "Low cost education platform for robotics,using open-source 3D printers and open-source hardware," Proc. ICERI2012 Conf., no. 978-84-616-0763-1, pp. 2769-2706, 2012.

[62] H. Costelha and C. Neves, "Technical database on robotics-based educational platforms for K-12 students," 18th IEEE Int. Conf. Auton. Robot Syst. Compet. ICARSC 2018, pp. 167-172, 2018.
[63] L. Payá, F. Amorós, L. Fernández, and O. Reinoso, An educational software to develop robot mapping and localization practices using visual information, vol. 10, no. PART 1. IFAC, 2013.

[64] V. Mavrovounioti, A. Chatzopoulos, M. Papoutsidakis, and D. Piromalis, "Implementation of an 2-wheel Educational Platform for STEM Applications," J. Multidiscip. Eng. Sci. Technol., vol. 5, no. 10, pp. 8944 8948,2018

[65] S. Alers and J. Hu, "AdMoVeo: A Robotic Platform," pp. 410-421, 2009.

[66] F. Wyffels, M. Hermans, and B. Schrauwen, "Building robots as a tool to motivate students into an engineering education," 1-st Slovak-Austrian Int. Conf. Robot. Educ., 2010.

[67] M. J. G. Trigo, P. Standen, and S. Cobb, "Why are educational robots not being used in Special Education schools despite proof that they are beneficial for their students ?," in 12th ICDVRAT with ITAG, 2018, pp. 19.

[68] F. Wikipedia, "Systems Development Life Cycle," 2018. [Online]. Available: https://en.wikipedia.org/wiki/Systems_development_life _cycle. [Accessed: 01-Jun-2018].

[69] Alexa Joyce and M. Dzoga, Science , technology , engineering and mathematics education Overcoming challenges in Europe. 2011.

[70] E. Dare, J. Ellis, and G. Roehrig, "Driven by Beliefs: Understanding Challenges Physical Science Teachers Face When Integrating Engineering and Physics.," J. PreCollege Eng. Educ., vol. 4, no. 2, pp. 47-61, 2014.

[71] M. Fuglei, "Teachers Face 4 Key Challenges with Problem-Based Learning," Concordia University Portland., 2017. [Online]. Available: https://education.cu-portland.edu/blog/classroomresources/practical-issues-with-problem-based-learning/. [Accessed: 26-Mar-2018]

[72] A. Massimo, "STEM education and the curriculum: Issues, tensions and challenges," Int. STEM, High-Level Policy Forum Evidence-based Sci. Educ. Dev. Ctries., no. May, pp. 26-27, 2015.

[73] S. Ravipati, "Biggest Challenges Facing K-12 STEM Ed PD, Accountability Systems, CS Curricula -- THE Journal," The Journal, 2017. [Online]. Available: https://thejournal.com/articles/2017/07/13/biggestchallenges-facing-k12-stem-ed.aspx. [Accessed: 26-Mar2018].

[74] S. Rhodes, "Challenges to STEM Education and How to Overcome Them -- College Planning \& Management," 1105 Media Inc, 2017. .

[75] S. Kemmis, R. Nixon, and R. McTaggart, The Action Research Planner. Doing Critical Participatory Action Research. Singapore: Springer Science+Business Media, 2014.

[76] S. Billett, C. Harteis, and H. Gruber, Learning Through Practice Models, Traditions, Orientations and Approaches. New York: Springer, 2010.

[77] C. A. Mertler, The Wiley Handbook of Action Research in Education. NJ, USA: John Wiley \& Sons, Inc., 2019. 
[78] S. Manesi and S. Betsi, "Collaborative action research projects: The role of communities of practice and mentoring in enhancing teachers' continuing professional development," Action Res. Educ., vol. 4, no. 4, pp. 109121, 2013.

[79] P. S. M. dos Santos and G. H. Travassos, Action Research Can Swing the Balance in Experimental Software Engineering, vol. 83. 2011.

[80] L. C. L. M. K. Morrison, “Action Researeh.” pp. 833880.

[81] J. Villanueva, "Flipped inclusion classroom: An action research," 21st Annu. Technol. Coll. Community Worldw. Online Conf., pp. 1-16, 2016.

[82] E. Calhoun, "Action Research for School Improvement Action Research at Work: A Teacher's Story," vol. 59, no. 6, pp. 18-24, 2002.

[83] W. Carr and S. Kemmis, Becoming Critical. Education, Knowledge and Action Research. Abingdon, UK: Taylor \& Francis e-Library, 2004.

[84] Y. L. Li, "Teachers in action research: Assumptions and potentials," Educ. Action Res., vol. 16, no. 2, pp. 251260, 2008 .

[85] L. Cohen, L. Manion, and K. Morrison, Research Methods in Education, 8th ed. London, UK: Routledge, 2018.

[86] O. Zuber-Skerritt, M. Fletcher, and J. Kearney, Professional Learning in Higher Education and Communities. Towards a New Vision for Action Research, 1st ed. London, UK: Palgrave, 2015.

[87] P. Newton and D. Burgess, "Exploring Types of Educational Action Research: Implications for Research Validity,” Int. J. Qual. Methods, vol. 7, no. 4, pp. 18-30, 2008

[88] H. Lune and B. L. Berg, Qualitative Research Methods for the Social Sciences, 9th ed. Essex, England: Pearson Education Limited, 2017.

[89] S. R. Klein, Action Research Methods Plain and Simple. New York: Palgrave Macmillan is, 2012.

[90] L. S. Norton, Action Research in Teaching and Learning. A practical guide to conducting pedagogical research in universities. Abingdon, UK: Taylor \& Francis e-Library, 2009

[91] J. Elliott, Action Research for educational change, 1st ed. Philadelphia: Open University Press, 1991.

[92] I. M. Santos, N. Ali, and A. Hill, "Students as Codesigners of a Virtual Learning Commons: Results of a Collaborative Action Research Study," J. Acad. Librariansh., vol. 42, no. 1, pp. 8-14, 2016.

[93] C. Gibbs, B. Kooyman, K. Marks, and J. Burns, "Mapping the Roadmap: Using Action Research to Develop an Online Referencing Tool," J. Acad. Librariansh., vol. 41, no. 4, pp. 422-428, 2015.

[94] M. Greeff and L. Coetzee, "Using action research for complex research initiatives," ICAST 2009 - 2nd Int. Conf. Adapt. Sci. Technol., pp. 331-338, 2009.

[95] Ortrun Zuber-Skerritt, Action Research In Higher Education. FALMER/KP, 1992.
[96] M. Bassey, Doing Qualitative Research in Educational Settings: CASE STUDY RESEARCH IN EDUCATIONAL SETTINGS. Buckingham: Open University Press, 1999.

[97] A. Asghar, R. Ellington, E. Rice, F. Johnson, and G. M. Prime, "Supporting STEM Education in Secondary Science Contexts," Interdiscip. J. Probl. Learn., vol. 6, no. 2,2012

[98] G. A. Fore, C. R. Feldhaus, B. H. Sorge, M. Agarwal, and K. Varahramyan, "Learning at the nano-level: Accounting for complexity in the internalization of secondary STEM teacher professional development," Teach. Teach. Educ., vol. 51, pp. 101-112, 2015.

[99] S. M. A. T. Interns, "Action research projects: Engineering," 2006.

[100] K. Magos, "The contribution of action-research to training teachers in intercultural education: A research in the field of Greek minority education," Teach. Teach Educ., vol. 23, no. 7, pp. 1102-1112, 2007.

[101] E. R. Okamura, "Action Research on Flipped Robotics Instruction," in 22nd Annual Technology, Colleges and Community Worldwide Online Conference, 2018, pp. 1-10

[102] R. R. Puentedura, "The Evolving Classroom: Action Research as Teaching Practice Four Defining Characteristics of Action Research Practical Nature Change-Oriented Part of a Cyclical Process Teachers are Active Researchers and Participants," 2014.

[103] S. W. Remit, "Professional development for teachers - inspiring students to take science, technology , engineering and mathematics: Petroc," no. May, 2015.

T. Saito, Y. Gunji, and Y. Kumano, "The Problem about Technology in STEM Education: Some Findings from Action Research on the Professional Development \& Integrated STEM Lessons in Informal Fields," K-12 STEM Educ., vol. 1, no. 2, pp. 85-100, 2015.

[104] M. Viloria, P. S. Gill, and S. Mireles, "Principal Preparation in STEM: An Action Research Project setting," J. Eff. Sch. Proj., vol. 23, pp. 62-68, 2016.

[105] K. Lesseig, D. Slavit, and T. H. Nelson, "Jumping on the STEM bandwagon: How middle grades students and teachers can benefit from STEM experiences," Middle Sch. J., vol. 48, no. 3, pp. 15-24, 2017.

[106] P. Michalopoulos, S. Mpania, A. Karatrantou, and C. Panagiotakopoulos, "Introducing STEM to Primary Education Students with Arduino and S4A.," in Hellenic Conference on Innovating STEM Education, 2016.

[107] M. Wilson, "Opportunities and Factors Affecting adoption of STEM Education: The Case of Gweru Polytechnic First Year Commerce Students. I INTRODUCTION,” Int. J. Bus. Mark. Manag., vol. 1, no. 5 , pp. 1-8, 2016.

[108] St. Papadakis, M. Kalogiannakis, V. Orfanakis, and N. Zaranis, "Novice Programming Environments. Scratch \& App Inventor: a first comparison,", In H. M. Fardoun and J. A. Gallud (Eds.) Proceedings of the 2014 Workshop on Interaction Design in Educational Environments., pp. 1-7, New York: ACM, 2014.

[109] St. Papadakis, M. Kalogiannakis, V. Orfanakis, and 
N. Zaranis, "Using Scratch and App Inventor for teaching introductory programming in Secondary Education. A case study," International Journal of Technology Enhanced Learning, 8(3-4), pp. 217-233. 2016.

[110] St. Papadakis, M. Kalogiannakis, V. Orfanakis, and N. Zaranis, "The Appropriateness of Scratch and App Inventor as Educational Environments for Teaching Introductory Programming in Primary and Secondary Education," International Journal of Web-Based Learning and Teaching Technologies (IJWLTT), 12(4), pp. 58-77. 2017

[111] N. Vidakis, A.-K. Barianos, A.-M. Trampas, St. Papadakis, M. Kalogiannakis, and K. Vassilakis, "Generating Education in-Game Data: The Case of an Ancient Theatre Serious Game," In B. McLaren, R. Reilly, S. Zvacek, \& J. Uhomoibhi (Eds), Proceedings of the 11th International Conference on Computer Supported Education (CSEDU 2019), Vol 1, 36-43, Heraklion, Crete, Greece, 2-4 May, 2019, 2019.
[112] St. Papadakis, M. Kalogiannakis, "Using Gamification for Supporting an Introductory Programming Course. The Case of ClassCraft in a Secondary Education Classroom," In A. Brooks, E. Brooks, N. Vidakis (Eds). Interactivity, Game Creation, Design, Learning, and Innovation. ArtsIT 2017, DLI 2017. Lecture Notes of the Institute for Computer Sciences, Social Informatics and Telecommunications Engineering, vol 229, (pp. 366-375), Switzerland, Cham: Springer, 2018

[113] St. Papadakis, "The use of computer games in classroom environment," International Journal of Teaching and Case Studies, 9(1), pp. 1-25, 2018.

[114] St. Papadakis, and M. Kalogiannakis, "Mobile educational applications for children. What educators and parents need to know," International Journal of Mobile Learning and Organisation (Special Issue on Mobile Learning Applications and Strategies), 11(3), pp. 256-277, 2017. 